\title{
Kormos, J. and Smith, A. M. (2012). Teaching Languages to Students with Specific Learning Differences. Bristol: Multilingual Matters. 232 p., ISBN 978-1-84769-620-5.
}

Reviewed by Florina Erbeli

Judit Kormos is a senior lecturer at the Department of Linguistics and English Language, Lancaster University. She is the editor of the volume Language Learners with Special Needs: An International Perspective. She was the principal investigator of a research and teacher-training project on the language learning processes of dyslexic and deaf learners in Hungary.

Anne Margaret Smith is a specialist tutor and assessor for students with specific learning differences. Her research interests include the assessment of cognitive functioning in multilingual learners. Her company, ELT well, offers advice and training for teachers and assessors who want to explore the overlap between language learning and specific learning differences.

For at least three different reasons Teaching Languages to Students with Specific Learning Differences can be highly recommended to language teachers, students and researchers:

1. This book is unique, because the coupling between basic mechanisms underlying different processes involved in language learning and numerous examples for enhancing language instruction becomes evident in each chapter.

2. This book covers all important subjects of teaching languages to students with specific learning differences (SpLDs), i.e. from overview of dyslexia and associated learning differences to discussing language learning difficulties that manifest in four basic language skills (listening, reading, speaking, writing), from the topic of different techniques and strategies used in language learning instruction when dealing with students with SpLDs to a remarkable array of issues concerning assessment and progression.

3. This book represents an adequate mixture of more recent research findings and the pedagogical implications of these findings. The book presents a concise review, even for the more advanced teacher or scientist, who will find additional valuable information in the reference list at the back of the book. 
Teaching Languages to Students with Specific Learning Differences provides a window into issues of language learning of students with specific learning differences. Because until recently language learning was an option open to only a small segment of the populace, an elitism surrounding foreign language learning was maintained in our schools. (Early) language learning was viewed for years as the province of a select portion of students: students considered 'college bound' were encouraged to take a foreign language course (LeLoup \& Ponterio, 1997). In light of modern learning theory, coupled with the current educational policy of inclusion and teachers' experience that all students can and should learn foreign languages in order to be fully functional in global society, the paradigm of language learning has changed, and so has the profile of the student population in the classrooms. Due to the transition of foreign language learning from an elite pursuit to a more mainstream educational goal, the students that populate foreign language classrooms have changed enormously over recent decades. Foreign language teachers face increasing numbers of students in their classrooms with diverse needs. We are seeing students exhibiting specific learning differences, who however must not be deprived of equal opportunities in education because of lack of a workable knowledge of another language. For a student who has an SpLD, foreign language learning can cause enormous anxiety and for some, it can be a humiliating experience. While in previous generations, these students may have opted out of language study, research shows that with appropriate accommodations, these students can be successful in learning another language. Although more resources are becoming available to the teachers who teach students with SpLDs, most foreign language teachers are ill-prepared to fulfil those specific differences (LeLoup \& Ponterio, 1997). Only very recently has the pre-service foreign language teacher curriculum started to provide preparation in the area of special education. At the onset of our first teaching experiences, many of us believed that we would be in front of the perfect class with highly motivated students sitting there, ready to absorb everything presented to them. Most of us have witnessed students who struggle to learn a foreign language even when they excel in another subject. At the same time, many of us probably have a story of how we have experienced success or disappointment instructing students who may be classified as students with SpLDs. Through these experiences, we know that a student who works hard to overcome whatever SpLD he/she faces can, and will, succeed. Are we prepared for the challenges we face due to diverse backgrounds, learners with SpLDs, or other language-related difficulties our students might bring to the classroom? This book intends to give an answer to precisely this question. It focuses on what teachers and curriculum developers could do with information 
about students with SpLD when dealing with learning foreign languages to improve language learning instruction. This book attempts to explain in detail the nature of SpLDs (dyslexia, dyspraxia, dyscalculia, ADHD, Asperger's syndrome) and how an SpLD separately or in combination affects general learning processes and the mechanisms of second language acquisition. Teachers need to have a good sense of how SpLDs are reflected in learning foreign languages if they are to understand key implications from research as well as the range of instructional assertions made about what will foster success in the language learning of students with SpLDs.

\section{The Organisation of the Book}

This book has nine chapters and concludes with appendices, references and an index. Each chapter starts with the contents and concludes with a list of key points, activities and suggestions for further reading. These supplementary materials show how the authors feel their chapters can be used in courses to stimulate critical thinking, application of knowledge, and further reading on a topic. Chapter 1 opens with an examination on discourses of disability to identify current dominant discourses. All of the discourses discussed in the book have a specific point of view on a disability as such to offer, but none provides a full picture, nor the basis of an optimal approach to supporting the efforts of students with an SpLD (Chanock, 2007). Only drawing constructively from the combination of discourses, scientific knowledge, experienced teachers, disability practitioners and students with SpLDs themselves can lead to terminology that promotes inclusive environment.

Chapter 2 explores the type of SpLD that has the most significant impact on language learning: dyslexia. It provides the contributions of researchers to increasing scientific knowledge of the biological, cognitive, behavioural and environmental causes of dyslexia and points out in which areas the students with dyslexia might be impaired.

Chapter 3 provides an overview of differences other than dyslexia. Those are the differences included in the definition of SpLDs currently used in the UK, i.e. dyspraxia, dyscalculia, ADHD. An additional learning difference, Asperger's syndrome, is described in the chapter as well.

Chapter 4 addresses the issue of what role cognitive and affective factors associated with SpLDs play in second language acquisition. Further on, difficulties with literacy related activities such as writing, spelling, reading, acquiring vocabulary and grammatical constructions students with SpLDs might experience are discussed. 
Chapter 5 attempts to argue the issue of importance to identify any indicators that may indicate the presence of an SpLD. Language teachers should be well informed about how SpLDs may be identified and accommodated, since SpLDs may manifest for the first time in the (foreign) language learning classroom. Students try to apply their usual up-to-that point successful learning strategies, but nevertheless do not succeed or excel in the new language context.

Chapters 6 and 7 deal with different types of accommodation for students with SpLDs used in or outside the classroom such as environment, curriculum, communication, classroom management, and techniques for language teaching. The research basis is briefly reviewed, followed by practical suggestions. The approach highly recommended when teaching students with SpLDs, the so-called multi-sensory structured learning, is highlighted and analysed.

Chapter 8 explores the evaluation procedures employed in the language classroom, i.e. assessment. Assessments are most frequently carried out by teachers; it is highly important for the teachers to be aware of how tests can be designed and modified to suit individual profiles of learners with SpLDs in classroom assessment.

Chapter 9 provides an epilogue synthesizing how the role of the language teacher is important in every step of language learning progress. That progress includes each stage of transition: becoming a pupil in a nursery school, later on in a secondary school and a student in a college or at university.

The book has been planned for at least five audiences. Teachers, teacher trainers, researchers, curriculum developers, and anyone interested in language teaching to students with SpLDs will want to read all the book chapters. The book is accessible to not only intrepid teachers but all language teachers wanting to know more about SpLDs and language teaching and about how to improve language teaching instruction. The book's intended audience is graduate students as well as novice teachers. If they are looking for a more streamlined explanation, a theoretical foundation can be built from Chapters 1 to 4 . Procedures for identifying students with SpLDs and ideas for adjusting schoolwork can be found in Chapters 5 through 8 . Strategies for facilitating transition and progression are addressed in Chapter 9.

\section{Towards Success in Language Learning}

This volume provides a window into the diversity of strategies and modifications used when teaching students with SpLDs. Regardless of researchers' differences on the topic of what amount of help is needed by students with SpLDs in a classroom, they do have shared understandings. They all believe 
that proficiency in a language other than one's own language is as important as literacy and numeracy skills. Perceiving causes of language learning differences as a great variety of factors that are crucial yet controllable helps teachers, parents and students themselves understand these learners better and assists in their successful inclusion in the language classroom.

This book exposes a wide array of issues for future research in Slovenia to resolve. One set of issue concerns the role of students themselves in the process of language learning. Students need a supportive classroom environment in which the teaching and assessment methods are adapted to their needs; however, their responsibility for their successful learning must not be diminished. Students themselves must be aware that they can only overcome their difficulties if they invest sufficient energy and effort into the process of language learning. In many cases, the level of effort and persistence needs to be higher than for students with no SpLDs in order to compensate for the differential functioning of cognitive abilities needed for language learning. Has students' awareness in Slovenia about this notion increased over the recent years? Have they ever had it?

A second set of issues relates to the development of curricula. Curriculum developers of pre-service teacher education, including foreign language teacher training must attempt to include diverse topics on inclusion and teaching languages to students with SpLDs in the curricula, and governments must provide adequate financial support. Besides preparing teachers to promote inclusion in schools, teacher educators from within universities and colleges must undertake the job of putting inclusive values into action in the culture, policies, and practices of their own institutions.

\section{To Conclude...}

Accommodations and modifications that will help students with SpLDs succeed along with a variety of teaching strategies to help these students learn a foreign language are continually being studied and researched. As you read Teaching Languages to Students with Specific Learning Differences, you will find important research findings that will assist you in reaching out to students who might be struggling with learning a foreign language and in turn, using instructional strategies that will facilitate their language learning. 


\section{References}

Chanock, K. (2007). How do we not communicate about dyslexia? The discourses that distance scientists, disabilities staff, ALL advisers, students and lecturers from one another. Journal of Academic Language and Learning, 1(1), 33-43.

LeLoup, J. W., \& Ponterio, R. (1997). Language Education and Learning Disabilites. Language Learning and Technology, 1(1), 2-4. 